\title{
Hepatitis B virus infection specially increases risk of liver metastasis in breast cancer patients: a propensity-matched analysis
}

\author{
Ping Yu", Peng Liu", Na Li", Xinhua Xie, Hailin Tang, Jiali Wu, Yanan Kong, Xiaoming Xie, Feng Ye \\ Department of Breast Oncology, Sun Yat-Sen University Cancer Center, State Key Laboratory of Oncology in South China, Collaborative \\ Innovation Center for Cancer Medicine, Guangzhou 510060, China \\ Contributions: (I) Conception and design: P Yu, P Liu, F Ye, X Xie; (II) Administrative support: F Ye, X Xie; (III) Provision of study materials or \\ patients: F Ye, X Xie; (IV) Collection and assembly of data: J Wu, N Li; (V) Data analysis and interpretation: N Li, H Tang, X Xie, Y Kong; (VI) \\ Manuscript writing: All authors; (VII) Final approval of manuscript: All authors. \\ \#These authors contributed equally to this work. \\ Correspondence to: Xiaoming Xie, Feng Ye. Department of Breast Oncology, State Key Laboratory of Oncology in South China, Sun Yat-Sen \\ University Cancer Center, 651 East Dongfeng Road, Guangzhou 510060, China. Email: xiexm@sysucc.org.cn; yefeng@sysucc.org.cn.
}

Background: Breast cancer and hepatitis B virus (HBV) infection are serious public health issues in China. But the effect of HBV infection on breast cancer remains unclear. The objective was to assess whether HBV infection was associated with prognosis of breast cancer.

Methods: A retrospective database of 1,924 invasive breast cancer patients from Sun Yat-sen University Cancer Center from 2008 to 2010 was established. Propensity score matching method was applied to balance baseline parameters. Logistic regression was used for identifying the independent risk factors of liver metastasis. Prognostic outcomes were evaluated via Kaplan-Meier analysis and Cox model.

Results: Primary evaluation of gross data suggested HBV infection was associated with much higher rate of liver metastasis. 642 patients were matched for analysis. The median follow-up time was about 69 months. Patients with HBV surface antigen $(\mathrm{HBsAg})(+)$ had a specially higher risk of liver metastasis aside of other distant organs than those with HBsAg (-). HBsAg $(-/+)$ was identified to be an independent risk factor of liver metastasis [odds ratio (OR), 2.651; 95\% confidence intervals (CI), 1.213-5.796; P=0.015]. HBsAg $(+)$ was associated with liver metastasis significantly in stage III or in estrogen receptor (ER) (+) and/or progesterone receptor (PR) (+), human epidermal growth factor receptor-2 (HER-2) (-) subtype. Meanwhile, patients with HBsAg $(+)$ had significant shorter liver metastasis-free survival (LMFS) compared with $\mathrm{HBsAg}$ $(-)$ patients $(\mathrm{P}=0.041)$. But the difference of overall survival (OS) between the HBsAg (-) and HBsAg $(+)$ groups reached statistically no significance $(\mathrm{P}=0.425)$. The multivariate analysis suggested $\mathrm{HBsAg}(+)$ could worsen the outcome of LMFS [hazards ratio (HR), 2.450; 95\% CI, 1.169-5.135; P=0.018].

Conclusions: In breast cancer, HBsAg (+) was associated with specially a higher rate of liver metastasis and thus worsened the LMFS. HBsAg (-/+) was an independent risk factor of liver metastasis.

Keywords: Hepatitis B virus (HBV); breast cancer; liver metastasis; survival

Submitted Aug 27, 2019. Accepted for publication Dec 26, 2019.

doi: $10.21037 /$ tcr.2020.01.63

View this article at: http://dx.doi.org/10.21037/tcr.2020.01.63 


\section{Introduction}

Breast cancer (BC) is the most common malignancy in the world. Incidence rate for distant metastasis accounts for approximately $6 \%$ of breast cancer diagnoses during 2008 to 2014 in United States (1). Metastatic spread is still a great challenge in spite of the favorable results after receiving standard treatments for early stage breast cancer patients $(2,3)$.

Hepatitis $\mathrm{B}$ virus (HBV) infection remains to be a serious global public health problem $(4,5)$. According to the statistics, in recent years the overall hepatitis B surface antigen (HBsAg) seropositive rate is $3.61 \%$ worldwide affecting more than 240 million people. China has been known as the primary drive of global epidemic of $\mathrm{HBV}$ infection, devoting for about $1 / 3$ of burden all over the world (4). A recent research on 15 million rural couples from China showed the HBsAg seropositive rate of $5.2 \%$ in 20-49 years old women (6).

Chronic infection with HBV is a kind of pathological status which can cause chronic liver damage such as changes of liver-related immunity and inflammation (7-11). HBV infection has been well recognized to be one of the major causes of hepatocellular cancer (HCC) and associated with non-Hodgkin's lymphoma (12-15). Moreover, some reports are obtainable regarding that whether $\mathrm{HBV}$ infection is associated with liver metastasis in some extrahepatic malignancies including colorectal cancer (CRC) and pancreatic cancer (PC). Interestingly, patients infected with HBV had lower liver metastasis rate than those without infection of $\mathrm{HBV}$, but the extrahepatic metastases rate rose in patients with HBV infection in CRC $(16,17)$. To the contrary, in PC patients synchronous liver metastasis rate increased along with HBV infection (18). Besides, studies revealed HBV infection also influenced the prognosis in CRC and PC (16-18). Nevertheless, in clinical practice many breast cancer patients with HBV infection occurred liver metastasis. The gap on the association between HBV infection and liver metastasis of breast cancer still exists, and the effect of $\mathrm{HBV}$ infection on prognosis in breast cancer remains unclear. Therefore, we conducted a cohort research to assess whether $\mathrm{HBV}$ infection was associated with liver metastasis and prognosis in breast cancer.

\section{Methods}

\section{Study population}

Consecutive invasive breast cancer patients in Sun Yat- sen University Cancer Center (SYSUCC) from January 2008 to December 2010 were reviewed retrospectively. Other inclusion criteria were included: received surgery in hospital; female. Exclusion criteria were as below: undergone surgery before admission; bilateral breast cancer; with second cancers other than breast cancer; had recurrence or metastasis; complicated with other types of hepatitis. They were followed up until June 30, 2017 or date of any cause death. This study passed the approval of the Research Ethics Committee in SYSUCC and informed consent was signed by every patient.

\section{Data collection}

Baseline parameters were collected including age, menstrual condition, family history, pathological type, histologic grade, tumor size, number of metastatic axillary lymph nodes, estrogen receptor (ER), progesterone receptor (PR), human epidermal growth factor receptor-2 (HER-2), surgical method, HBsAg status and date of distant metastases including liver metastasis, death or last follow-up.

\section{Clinical or patbological staging and intrinsic subtyping}

The clinical or pathological stages of the disease were determined by TNM staging according to the seventh edition of the American Joint Committee on Cancer (AJCC) system (19).

Information on ER, PR and HER-2 was extracted according to American Society of Clinical Oncology guideline recommendations $(20,21)$. ER, PR positive was defined as $\geq 1 \%$ tumor cells presenting positive nuclear staining by immunohistochemistry (IHC) assay. HER-2 positive was determined as IHC $3+$ or fluorescence in situ hybridization positive (HER-2 amplification). The breast cancer molecular subtypes were grouped as below: ER $(+)$ and/or PR (+), HER-2 (-);ER (+) and/or PR (+), HER-2 (+); ER (-) and PR (-), HER-2 (+); ER (-) and PR (-), HER-2 (-).

\section{HBsAg test}

All patients received routine serum test for HBV infection before surgery by immunoenzyme labeling method. Serum samples were gathered and then centrifuged for using. The diagnostic kit from Shanghai Kehua Bioengineering Company was approved for clinical diagnostic usage. 


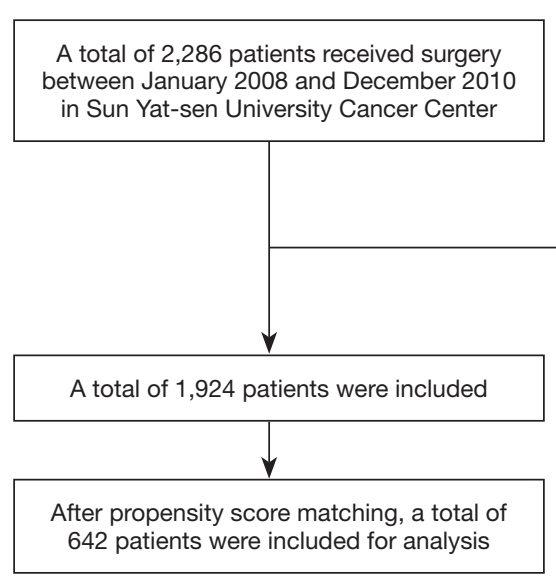

Figure 1 Flow chart of the patient selection.

\section{Follow-up and assessment of disease}

Patients' follow-up was performed via outpatient medical records and telephone counseling. Generally, according to National Comprehensive Cancer Network (NCCN) Guidelines of invasive breast cancer, patients received routine examinations including blood regular and biochemistry test, tumor biomarkers and ultrasonography of breast, abdomen, uterus and adnexa for follow-up visit. When liver metastases were suspected, a specific examination such as a computed tomography scan, magnetic resonance imaging or pathological biopsy was added. All of the liver metastatic patients were diagnosed according to serology test [carcino-embryonic antigen (CEA), carbohydrate antigen 153 (CA153), alpha fetoprotein (AFP)] and imaging test [computed tomography (CT) scan or magnetic resonance imaging (MRI) scan or positron emission tomography-computed tomography (PET-CT) scan] and confirmed through pathological biopsy and latter anti-tumor treatment and long-term follow-up.

\section{Statistical analysis}

Propensity scores were calculated for every patient by logistic regression using the covariates: age, menstrual condition, family history, pathological type, histologic grade, tumor size, number of metastatic lymph nodes, ER, PR, HER-2, surgical method with 1 to 2 matching ratios. The main end points in the research were liver metastasisfree survival (LMFS) and overall survival (OS). LMFS determined as time to liver metastasis, was calculated from the date of diagnosis to the date of liver metastasis or last follow-up. OS was figured up from the date of diagnosis to the date of any cause death or last follow-up. The continuous data were described via median and range. The categorical data were exhibited by numbers and percentages. Chi-square test was adopted to evaluate categorical data. Logistic regression model was used to evaluate odds ratio (OR) and $95 \%$ confidence intervals (CIs) for identifying the independent risk factors associated with liver metastasis. Age, menstrual condition, family history, histologic grade, tumor size, number of metastatic lymph nodes, ER, PR, HER-2, surgical method and HBsAg (-/+) were included as variables. Kaplan-Meier curve was estimated for survival analyses, meanwhile the differences between the groups were evaluated by log-rank test. A Cox proportional hazards model was used to identify the independent factors associated with LMFS, OS. A two-tailed P value of $<0.05$ was deemed to significant statistically. All the statistical analyses were carried out by the SPSS, version 22.0 (SPSS Inc., Chicago, IL, USA).

\section{Results}

\section{Baseline characteristics}

In total, 1,924 consecutive patients diagnosed invasive breast cancer were enrolled, including 215 (11.2\%) HBsAg (+) patients; 642 patients were selected for analysis by propensity score matching (PSM) including 214 (33.3\%) HBsAg (+) patients. The whole selection process was shown in Figure 1. The median age was 48 years (rang, 22-85 years); $416(64.8 \%)$ patients were younger than 50 years. Patient characteristics and correlations between HBsAg 
$(-/+)$ and clinicopathological parameters before and after PSM were shown in Tables 1,2. For the matched cohort, there was no significant difference demonstrated concerning age, menstrual condition, family history, pathological type, histologic grade, tumor size, number of metastatic lymph nodes, ER, PR, HER-2, surgical methods between HBsAg (-) and HBsAg (+) groups (all $\mathrm{P}>0.05$ ). Moreover, compared with HBsAg (-) group, HBsAg (+) group suffered more liver metastasis in both original and selected cohort $(\mathrm{P}<0.05)$. There was no difference on extrahepatic metastases observed between two groups in selected data $(\mathrm{P}=0.199)$.

\section{Failure patterns}

The median follow-up time was about 69 months (range, 1-119 months). Death and liver metastasis happened in 81 (12.6\%), 31 (4.8\%) of the 642 patients. Up to the last time of follow-up, 16/214 (7.5\%) patients in HBsAg (-) group and $15 / 428(3.5 \%)$ patients in HBsAg (+) group developed liver metastasis. Moreover, $31 / 214(14.5 \%)$ patients and $50 / 428$ (11.7\%) patients died in HBsAg (-) and HBsAg (+) group, respectively.

\section{Association between HBs Ag (-/+) and liver metastasis}

In the univariate logistic regression analysis, there was a significant association statistically found between $\mathrm{HBsAg}$ $(-/+)$, tumor size, number of metastatic lymph nodes and liver metastasis (Table 3, all $\mathrm{P}<0.05$ ). Meanwhile, to adjust for various risk factors, multivariate analysis was performed, which result accorded with that of the univariate analysis. It revealed that $\mathrm{HBsAg}(-/+)$ could be identified as an independent risk factor of liver metastasis (OR, 2.651; 95\% CI, 1.213-5.796; $\mathrm{P}=0.015)$. Patients in HBsAg (+) group had a much higher risk of liver metastasis than those in HBsAg (-) group. In addition, tumor size, number of metastatic lymph nodes were also independent risk factors of liver metastasis.

After stratified according to clinical stages, multivariate analysis revealed that $\mathrm{HBsAg}(+)$ was related with liver metastasis significantly in breast cancer patients of stage III (OR, 3.892; 95\% CI, 1.450-10.451; P=0.007; Table 4), and the results of patients with $\mathrm{HBsAg}(+)$ in stage I, II had no significantly difference from those with HBsAg (-) $(\mathrm{P}=0.488)$. Besides, HBsAg $(-/+)$ was identified to be a risk

Table 1 Baseline characteristics of breast cancer patients with or serum HBsAg (-/+) before matched

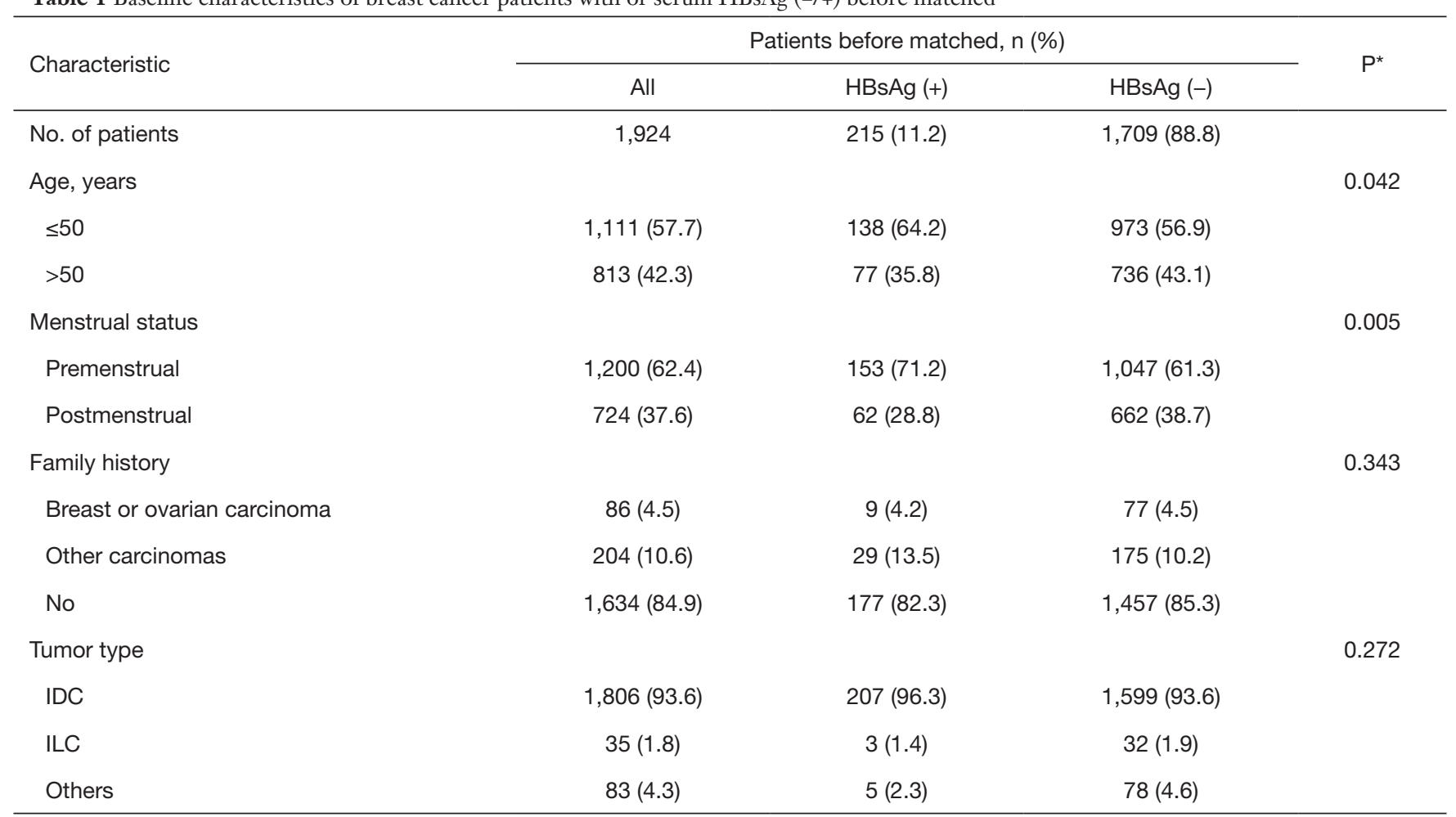

Table 1 (continued) 
Table 1 (continued)

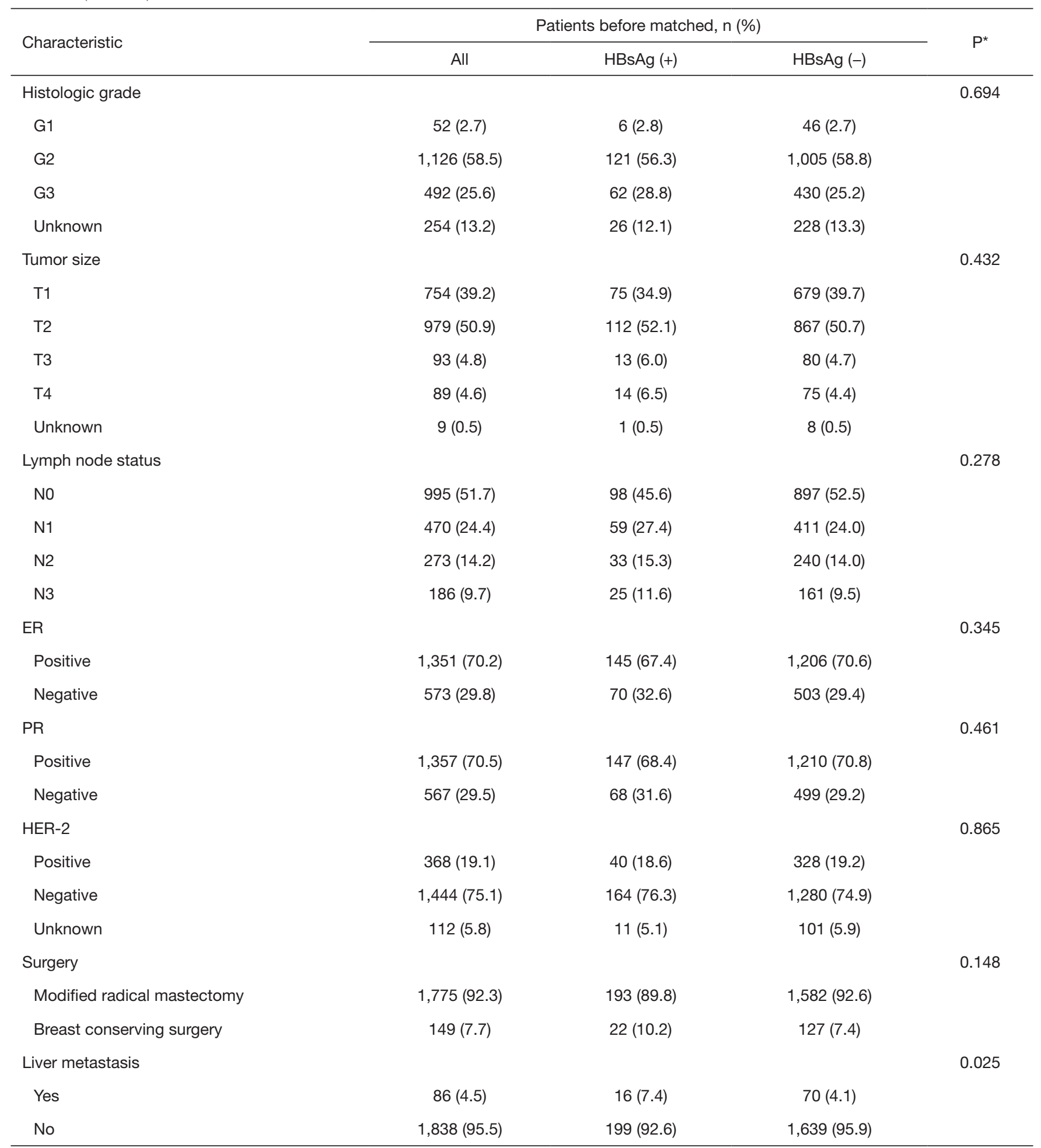

*, using Chi-squared test, $\mathrm{P}<0.05$ was considered statistically significant. IDC, invasive ductal carcinoma; ILC, invasive lobular carcinoma; $\mathrm{ER}$, estrogen receptor, PR, progesterone receptor, HER-2, human epidermal growth factor receptor-2; HBsAg, hepatitis B surface antigen. 
Table 2 Baseline characteristics of breast cancer patients with serum HBsAg (-/+) after matched

\begin{tabular}{|c|c|c|c|c|}
\hline Characteristic & \multicolumn{3}{|c|}{ Patients after matched, n (\%) } & $P^{*}$ \\
\hline No. of patients & $642(100.0)$ & $214(33.3)$ & $428(66.7)$ & \\
\hline Age, years & & & & 0.770 \\
\hline$\leq 50$ & $416(64.8)$ & $137(64.0)$ & $279(65.2)$ & \\
\hline Menstrual status & & & & 0.618 \\
\hline Premenstrual & $464(72.3)$ & $152(71.0)$ & $312(72.9)$ & \\
\hline Postmenstrual & $178(27.7)$ & $62(29.0)$ & $116(27.1)$ & \\
\hline Family history & & & & 0.635 \\
\hline No & $538(83.8)$ & $176(82.2)$ & $362(84.6)$ & \\
\hline Tumor type & & & & 0.865 \\
\hline IDC & $620(96.6)$ & $206(96.3)$ & $414(96.7)$ & \\
\hline ILC & $7(1.1)$ & $2(0.9)$ & $4(0.9)$ & \\
\hline Others & $15(2.3)$ & $5(2.3)$ & $10(2.3)$ & \\
\hline Histologic grade & & & & 0.464 \\
\hline G1 & $14(2.2)$ & $6(2.8)$ & $8(1.9)$ & \\
\hline G2 & $365(56.9)$ & $120(56.1)$ & $245(57.2)$ & \\
\hline T3 & $47(7.3)$ & $13(6.1)$ & $34(7.9)$ & \\
\hline T4 & $37(5.8)$ & $13(6.1)$ & $24(5.6)$ & \\
\hline Unknown & $2(0.3)$ & $1(0.5)$ & $1(0.3)$ & \\
\hline Lymph node status & & & & 0.913 \\
\hline No & $292(45.5)$ & $98(45.8)$ & $194(45.3)$ & \\
\hline N1 & $174(27.1)$ & $59(27.6)$ & $115(26.9)$ & \\
\hline N2 & $108(16.8)$ & $33(15.4)$ & $75(17.5)$ & \\
\hline N3 & $68(10.6)$ & $24(11.2)$ & 44 (10.3) & \\
\hline ER & & & & 0.636 \\
\hline Positive & $427(66.5)$ & $145(67.8)$ & $282(65.9)$ & \\
\hline Negative & $215(33.5)$ & $69(32.2)$ & $146(34.1)$ & \\
\hline
\end{tabular}

Table 2 (continued) 
Table 2 (continued)

\begin{tabular}{|c|c|c|c|c|}
\hline Characteristic & \multicolumn{3}{|c|}{ Patients after matched, n (\%) } & $P^{*}$ \\
\hline PR & & & & 0.904 \\
\hline Positive & $443(69.0)$ & $147(68.7)$ & $296(69.2)$ & \\
\hline Negative & $199(31.0)$ & $67(31.3)$ & $132(30.8)$ & \\
\hline Positive & $116(18.1)$ & $40(18.7)$ & $76(17.8)$ & \\
\hline Negative & $493(76.8)$ & $163(76.2)$ & $330(77.1)$ & \\
\hline Unknown & $33(5.1)$ & $11(5.1)$ & $22(5.1)$ & \\
\hline Surgery & & & & 0.565 \\
\hline Liver metastasis & & & & 0.027 \\
\hline Yes & $31(4.8)$ & $16(7.5)$ & $15(3.5)$ & \\
\hline No & $611(95.2)$ & $198(92.5)$ & $413(96.5)$ & \\
\hline Extrahepatic metastases & & & & 0.199 \\
\hline Yes & $56(8.7)$ & $23(10.7)$ & $33(7.7)$ & \\
\hline No & $586(91.3)$ & $191(89.3)$ & $395(92.3)$ & \\
\hline
\end{tabular}

*, using Chi-squared test, $\mathrm{P}<0.05$ was considered statistically significant. IDC, invasive ductal carcinoma; ILC, invasive lobular carcinoma; ER, estrogen receptor, PR, progesterone receptor, HER-2, human epidermal growth factor receptor-2; HBsAg, hepatitis B surface antigen.

factor for the patients of ER (+) and/or PR (+) HER-2 (-) subtype $(\mathrm{P}=0.020$, Table 4$)$, and there was a very slight trend in ER (+) and/or PR (+) HER-2 (+) subtype ( $\mathrm{P}=0.352)$. No statistically significance was found in ER (-) and PR (-) HER-2 (+), ER (-) and PR (-) HER-2 (-) subtypes (all $\mathrm{P}>0.05)$

\section{Survival analysis}

For the matched 642 patients, the 5-year OS, LMFS rates were $88.0 \%$ and $95.0 \%$ respectively. Besides the 5 -year LMFS (96.6\% vs. 92.3\%; $\mathrm{P}=0.041$; Figure $2 A$ ) rate for patients with $\mathrm{HBsAg}(-)$ was significantly slightly higher than that for patients with HBsAg $(+)$. However, the difference in the 5 -year OS $(88.2 \%$ vs. $85.9 \%$; $\mathrm{P}=0.425$; Figure $2 B$ ) rates between the HBsAg (-) and HBsAg (+) groups reached no statistical significance. Adjusting for various prognostic factors, multivariate analysis showed the result that patients with HBsAg (+) could worsen the outcome of LMFS [hazards ratio (HR), 2.450; 95\% CI, 1.169-5.135; $\mathrm{P}=0.018]$ (Table 5).

\section{Discussion}

HBV infection has been already reported to be associated with liver metastasis of some malignancies. However, the effect of $\mathrm{HBV}$ infection upon breast cancer patients remains unclear.

In our study, the liver metastasis and survival condition of 642 breast cancer cases were analyzed retrospectively using propensity score matching method. HBsAg (+) was associated with specially higher rate liver metastasis in breast cancer and thus worsened the LMFS. HBsAg (-/+) was an independent risk factor of liver metastasis in breast cancer.

Considering the number of HBsAg (-) group was far more than that of HBsAg (+) group and the imbalance between two groups' covariates existed in original data, 
Table 3 Logistic regression of factors associated with liver metastasis

\begin{tabular}{|c|c|c|c|c|}
\hline Variable & \multicolumn{2}{|c|}{ Univariate analysis } & \multicolumn{2}{|c|}{ Multivariate analysis } \\
\hline Age & $1.013(0.476-2.154)$ & 0.973 & & \\
\hline Menstrual status & $0.613(0.247-1.519)$ & 0.290 & & \\
\hline \multicolumn{5}{|l|}{ Family history } \\
\hline $\mathrm{BC}$ or $\mathrm{OC}$ & $0.627(0.082-4.773)$ & 0.652 & & \\
\hline Other carcinomas & $0.754(0.316-3.189)$ & 0.897 & & \\
\hline \multicolumn{5}{|l|}{ Histologic grade } \\
\hline G1/unknown & 1 (reference) & & 1 (reference) & \\
\hline \multicolumn{5}{|l|}{ Tumor size } \\
\hline T1/unknown & 1 (reference) & & 1 (reference) & \\
\hline T2 & $4.329(1.254-14.974)$ & 0.020 & $4.468(1.236-16.151)$ & 0.022 \\
\hline T3 & 11.366 (2.733-47.262) & 0.001 & 8.288 (1.760-39.026) & 0.007 \\
\hline $\mathrm{T} 4$ & $12.135(2.767-53.219)$ & 0.001 & $4.801(0.938-24.578)$ & 0.050 \\
\hline \multicolumn{5}{|l|}{ Lymph node status } \\
\hline No & 1 (reference) & & 1 (reference) & \\
\hline $\mathrm{N} 1$ & 6.501 (1.788-23.639) & 0.004 & 6.045 (1.579-23.134) & 0.009 \\
\hline Negative & 1 (reference) & & & \\
\hline Positive & $2.098(0.924-4.766)$ & 0.077 & & \\
\hline Unknown & 2.495 (0.699-8.904) & 0.159 & & \\
\hline Surgery & $1.082(0.318-3.678)$ & 0.900 & & \\
\hline HBsAg & $2.225(1.078-4.592)$ & 0.031 & $2.651(1.213-5.796)$ & 0.015 \\
\hline
\end{tabular}

*, using Chi-squared test, $\mathrm{P}<0.05$ was considered statistically significant. IDC, invasive ductal carcinoma; ILC, invasive lobular carcinoma; ER, estrogen receptor, PR, progesterone receptor, HER-2, human epidermal growth factor receptor-2; HBsAg, hepatitis B surface antigen; $\mathrm{BC}$, breast carcinoma; OC, ovarian carcinoma. 
Table 4 Univariate and multivariate logistic regression analyses for the association between serum HBsAg $(-/+)$ and liver metastasis in various clinical stages and intrinsic subtypes

\begin{tabular}{|c|c|c|c|c|}
\hline Subgroup & \multicolumn{2}{|c|}{ Univariate analysis } & \multicolumn{2}{|c|}{ Multivariate analysis } \\
\hline \multicolumn{5}{|l|}{ Clinical stages* } \\
\hline $\mathrm{I} / \mathrm{II}$ & $1.567(0.415-5.924)$ & 0.508 & $1.631(0.409-6.493)$ & 0.488 \\
\hline III & $2.931(1.193-7.202)$ & 0.019 & $3.892(1.450-10.451)$ & 0.007 \\
\hline ER (+) and/or PR (+) HER-2 (-) & $2.571(0.937-7.056)$ & 0.067 & $4.248(1.250-14.433)$ & 0.020 \\
\hline ER (+) and/or PR (+) HER-2 (+) & $1.087(0.186-6.367)$ & 0.926 & $6.084(0.136-272.056)$ & 0.352 \\
\hline ER $(-)$ and PR (-) HER-2 (+) & $3.692(0.305-44.692)$ & 0.305 & $1.304(0.098-8.672)$ & 0.977 \\
\hline ER (-) and PR (-) HER-2 (-) & $1.300(0.112-15.144)$ & 0.834 & $0.587(0.024-14.354)$ & 0.744 \\
\hline
\end{tabular}

*, tumor size and lymph node status were not involved in the multivariate analyses; ", hormone receptor status and HER-2 status were not involved in the multivariate analyses. ER, estrogen receptor, PR, progesterone receptor, HER-2, human epidermal growth factor receptor-2; HBsAg, hepatitis B surface antigen.
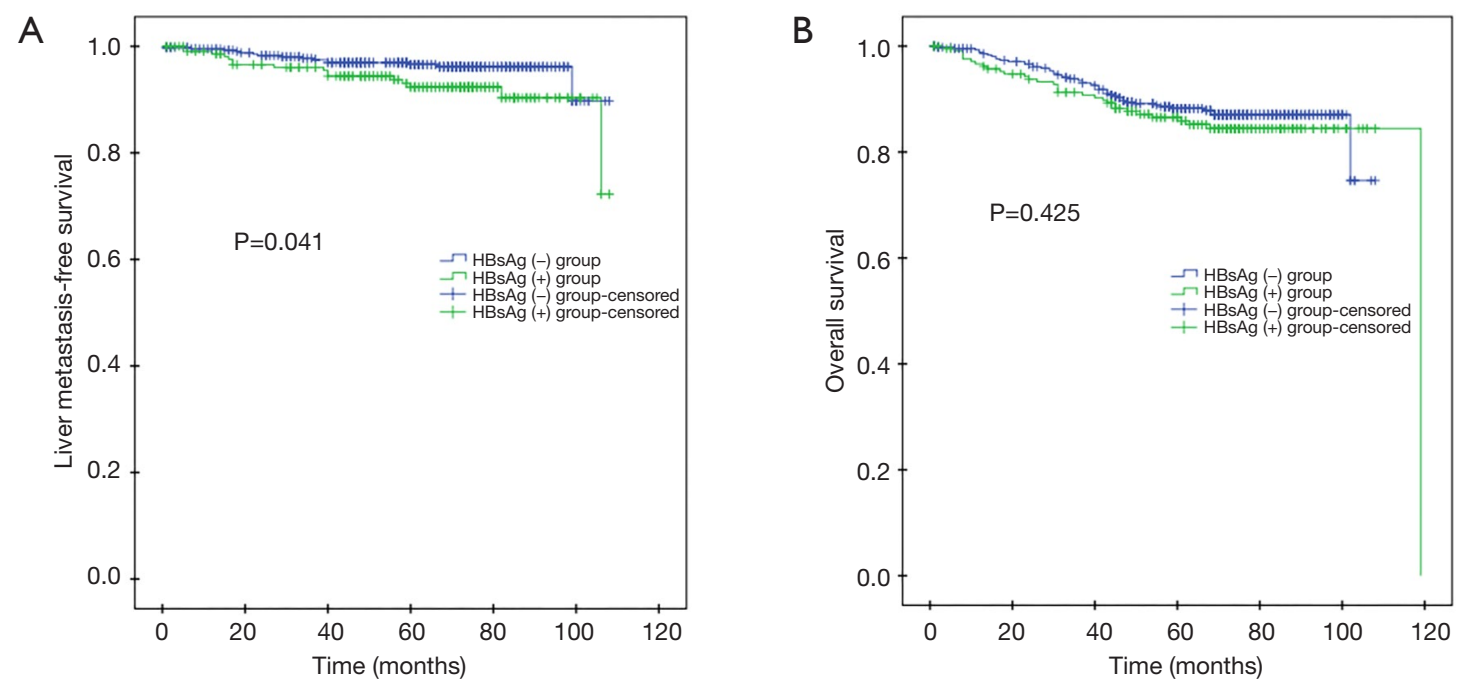

Figure 2 Kaplan-Meier OS (A), LMFS (B) curves for the 642 patients with HBsAg (-/+). OS, overall survival; LMFS, liver metastasis-free survival; HBsAg, hepatitis B surface antigen.

PSM method was used to equilibrate baseline parameters and then match patients in order to eliminate these errors.

Tumor development is derived from the complicated interactions among tumor intrinsic properties, the host microenvironment and inflammatory response (22-24). Under the drive of some factors the tumor cells leave the original site, migrate via the bloodstream and lymphatic drainage, settled in the suitable target organ, and then invade the surrounding tissue to form a new metastatic site $(22,25)$. HBV, as one of oncogenic viruses, has been found not only to participate in the etiology of cancers and also to play the vital part in cancer metastasis (26). Several possible mechanisms are considered to be connected with the progression and migration of tumor cells. Firstly, HBV directly assists breast cancer cells colonization to the liver. Binding with HBV X-interacting protein (HBXIP) which 
Table 5 Cox regression analyses of serum HBsAg $(-/+)$ for LMFS in 642 patients

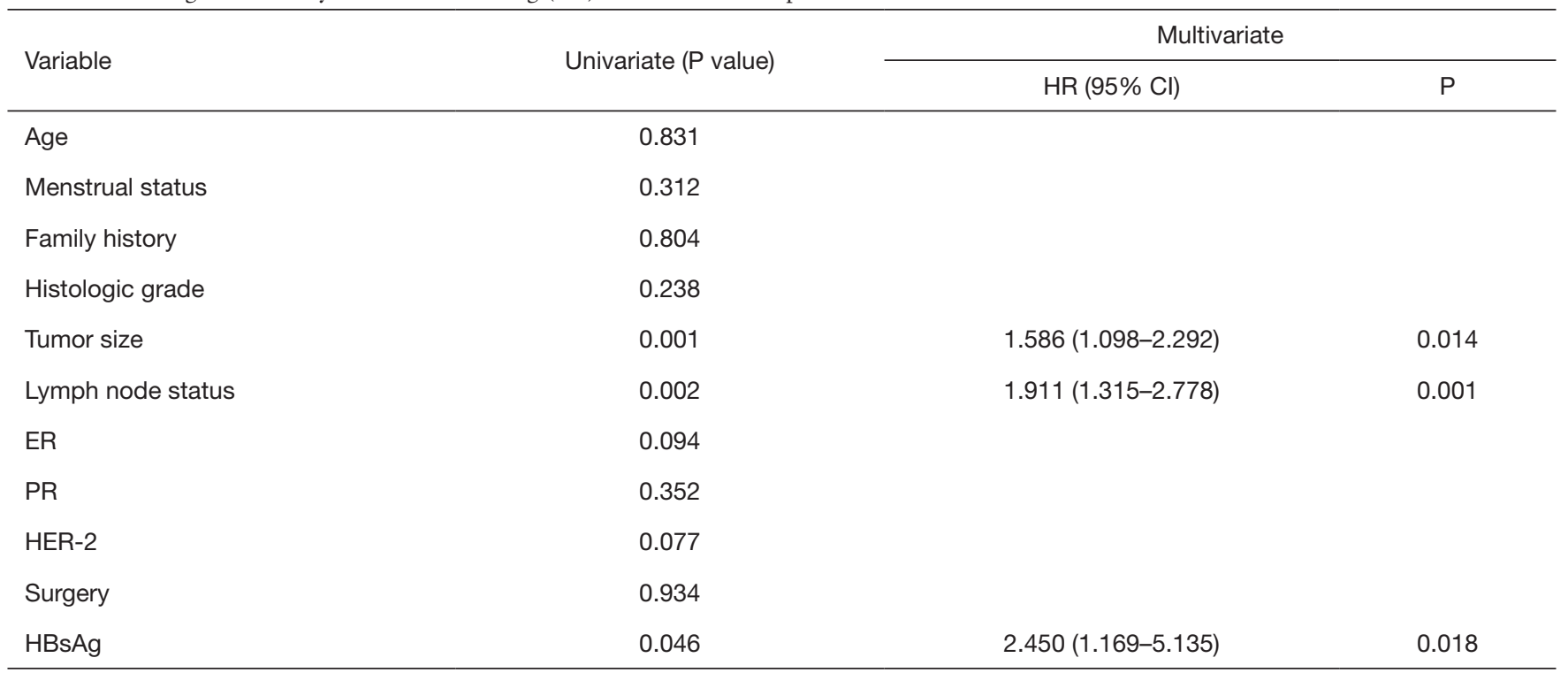

ER, estrogen receptor, PR, progesterone receptor, HER-2, human epidermal growth factor receptor-2; HBsAg, hepatitis B surface antigen, LMFS, liver metastasis-free survival.

expresses in breast cancer (27), HBV-encoded $\mathrm{X}$ antigen $(\mathrm{HBx})$ could mediate epithelial-mesenchymal transition (EMT) program, therefore facilitating tumor invasion and migration. The EMT program is started through activating the TWIST promoter and the protein kinase B/ phosphatidylinositol 3-kinase/glycogen synthase kinase-3b (Akt/PI3-K/GSK-3b) signaling pathway by HBx (28-31). Secondly, chronic inflammation caused by HBV infection contributes to imbalance of cytokines such as interleukin 6 (IL-6) (32), IL-27 (33), transforming growth factor beta $(\mathrm{TGF}-\beta)(34)$ in the liver microenvironment, participating in tumor cells EMT program and promoting metastases (35-38). For example, IL-6 produced by immune cells activates the Src homology 2 (SH2)-containing protein tyrosine phosphatase-2 (SHP-2)-Ras-extracellular signalregulated kinase (ERK), Janus kinase (JAK)-signal transducer and activator of transcription 3 (STAT3) and PI3K-Akt pathways, leading to tumor cells proliferation, EMT, invasion, angiogenesis and finally metastasis (36). Thirdly, chronic HBV infection triggers immune tolerance in liver, which creates a favorable environment for cancer cells survival. During long-term chronic HBV antigenic stimulation, virus-specific $\mathrm{T}$ cells become exhausted and functionally impaired. Meanwhile, regulatory T cells (Tregs) produced via activation of Notch pathway suppress CD4/
CD8 $\mathrm{T}$ cells in reverse via releasing IL-10, TGF- $\beta$. These together lead to tolerance, allowing tumor cells colonization without immune clearance $(9,39,40)$.

HBV infection also had some impact on survival in several malignancies. So far people couldn't draw a coincident conclusion about the effect of $\mathrm{HBV}$ infection on survival of CRC in previous studies $(16,17)$. Interestingly, Wei et al. found chronic hepatitis B and non-HBV infection group showed significantly better OS than inactive $\mathrm{HBsAg}$ carriers group (18). In our study, HBsAg (+) group showed significant worse LMFS than HBsAg (-) group, which was in line with higher liver metastasis rate in $\mathrm{HBsAg}(+)$ group. The overall survival between the HBsAg (-) and HBsAg $(+)$ groups reached no statistical difference, which might attribute to the small size of sample and need prospective studies to figure it out.

On account of the retrospective feature of our study, there were some deficiencies. Above all, although consecutive patients were chosen and eligibility criteria were carried out to minimize the bias, a selection bias was inevitable. In addition, the size of sample was limited and from one center, much bigger samples and work are included in future.

Therefore, further prospective trials and basic laboratory experiments on mechanisms are required to make certain 
how HBV infection affects breast cancer progression, which may provide clinicians a new strategy to evaluate and prevent the risks for liver metastasis and death.

\section{Conclusions}

HBsAg (+) was associated with a specially higher rate liver metastasis in breast cancer and thus worsened the LMFS. HBsAg $(-/+)$ could be an independent risk factor of liver metastasis in breast cancer patients. By far, it is the first research to demonstrate the effect of $\mathrm{HBV}$ infection on liver metastasis in breast cancer.

\section{Acknowledgments}

We thank the patients, their families, and the investigators who participated in this study.

Funding: This work was sponsored by funds from the National Natural Science Foundation of China (81872152, to X Xie), the Natural Science Foundation of Guangdong (2018A0303130285, to F Ye) and Science and Technology Planning Projects of Guangdong (2017A020215197, to F Ye).

\section{Footnote}

Conflicts of Interest: All authors have completed the ICMJE uniform disclosure form (available at http://dx.doi. org/10.21037/tcr.2020.01.63). The authors have no conflicts of interest to declare.

Ethical Statement: The authors are accountable for all aspects of the work in ensuring that questions related to the accuracy or integrity of any part of the work are appropriately investigated and resolved. The study was conducted in accordance with the Declaration of Helsinki (as revised in 2013). This study passed the approval of the Research Ethics Committee in Sun Yat-sen University Cancer Center and informed consent was signed by every patient.

Open Access Statement: This is an Open Access article distributed in accordance with the Creative Commons Attribution-NonCommercial-NoDerivs 4.0 International License (CC BY-NC-ND 4.0), which permits the noncommercial replication and distribution of the article with the strict proviso that no changes or edits are made and the original work is properly cited (including links to both the formal publication through the relevant DOI and the license). See: https://creativecommons.org/licenses/by-nc-nd/4.0/.

\section{References}

1. Siegel RL, Miller KD, Jemal A. Cancer statistics, 2019. CA Cancer J Clin 2019;69:7-34.

2. DeSantis CE, Ma J, Gaudet MM, et al. Breast cancer statistics, 2019. CA Cancer J Clin 2019;69:438-51.

3. Schwartz RS, Erban JK. Timing of Metastasis in Breast Cancer. N Engl J Med 2017;376:2486-8.

4. Schweitzer A, Horn J, Mikolajczyk RT, et al. Estimations of worldwide prevalence of chronic hepatitis B virus infection: a systematic review of data published between 1965 and 2013. Lancet 2015;386:1546-55.

5. Ott JJ, Horn J, Krause G, et al. Time trends of chronic HBV infection over prior decades - A global analysis. J Hepatol 2017;66:48-54.

6. Long Z, Wang YY, Huang YJ, et al. Status of HBsAg seroprevalence in 15 million rural couples in China: a cross-sectional study. Sci Rep 2017;7:42822.

7. Fattovich G, Bortolotti F, Donato F. Natural history of chronic hepatitis B: special emphasis on disease progression and prognostic factors. J Hepatol 2008;48:335-52.

8. Jung MC, Pape GR. Immunology of hepatitis B infection. Lancet Infect Dis 2002;2:43-50.

9. Shin EC, Sung PS, Park SH. Immune responses and immunopathology in acute and chronic viral hepatitis. Nat Rev Immunol 2016;16:509.

10. Gish RG, Given BD, Lai CL, et al. Chronic hepatitis B: Virology, natural history, current management and a glimpse at future opportunities. Antiviral Res 2015;121:47-58.

11. Gil-Garcia AI, Madejon A, Francisco-Recuero I, et al. Prevalence of hepatocarcinoma-related hepatitis B virus mutants in patients in grey zone of treatment. World J Gastroenterol 2019;25:5883-96.

12. Engels EA, Cho ER, Sun HJ. Hepatitis B virus infection and risk of non-Hodgkin lymphoma in South Korea: a cohort study. Lancet Oncol 2010;11:827-34.

13. El-Serag HB. Epidemiology of viral hepatitis and hepatocellular carcinoma. Gastroenterology 2012;142:1264-73.e1.

14. Baatarkhuu O, Gerelchimeg T, Munkh-Orshikh D, et al. Epidemiology, Genotype Distribution, Prognosis, Control, and Management of Viral Hepatitis B, C, D, and Hepatocellular Carcinoma in Mongolia. Euroasian J Hepatogastroenterol 2018;8:57-62.

15. Kim M, Kyung Lee $Y$, Park B, et al. Hepatitis virus B and $\mathrm{C}$ infections are associated with an increased risk of nonHodgkin lymphoma: A nested case-control study using a national sample cohort. J Med Virol 2019. [Epub ahead of 
print].

16. Zhao Y, Lin J, Peng J, et al. Hepatitis B Virus Infection Predicts Better Survival In Patients With Colorectal Liveronly Metastases Undergoing Liver Resection. J Cancer 2018;9:1560-7.

17. Qiu HB, Zhang LY, Zeng ZL, et al. HBV infection decreases risk of liver metastasis in patients with colorectal cancer: A cohort study. World J Gastroenterol 2011;17:804-8.

18. Wei XL, Qiu MZ, Chen WW, et al. The status of HBV infection influences metastatic pattern and survival in Chinese patients with pancreatic cancer. J Transl Med 2013;11:249.

19. Edge SB, Compton CC. Edge SB, Compton CCThe American Joint Committee on Cancer: the 7 th edition of the AJCC cancer staging manual and the future of TNM. Ann Surg Oncol 17(6): 1471-1474. Ann Surg Oncol 2010;17:1471-4.

20. Lambein K, Van BM, Denys H, et al. 2013 update of the American Society of Clinical Oncology/ College of American Pathologists guideline for human epidermal growth factor receptor 2 testing: impact on immunohistochemistry-negative breast cancers. J Clin Oncol 2014;32:1856-7.

21. Hammond ME, Hayes DF, Dowsett M, et al. American Society of Clinical Oncology/College Of American Pathologists guideline recommendations for immunohistochemical testing of estrogen and progesterone receptors in breast cancer. J Clin Oncol 2010;28:2784-95.

22. Fidler IJ. The pathogenesis of cancer metastasis: the 'seed and soil' hypothesis revisited. Nat Rev Cancer 2003;3:453.

23. Balkwill F, Mantovani A. Inflammation and cancer: back to Virchow? Lancet 2001;357:539-45.

24. Mueller MM, Fusenig NE. Friends or foes - bipolar effects of the tumour stroma in cancer. Nat Rev Cancer 2004;4:839-49.

25. Hosseini H, Obradović MM, Hoffmann M, et al. Early dissemination seeds metastasis in breast cancer. Nature $2017 ; 540$.

26. Akram N, Imran M, Noreen M, et al. Oncogenic Role of Tumor Viruses in Humans. Viral Immunol 2017;30:20-7.

27. Fujii R, Zhu C, Wen Y, et al. HBXIP, cellular target of hepatitis $\mathrm{B}$ virus oncoprotein, is a regulator of centrosome dynamics and cytokinesis. Cancer Res 2006;66:9099.

28. Ye X, Brabletz T, Kang Y, et al. Upholding a role for EMT in breast cancer metastasis. Nature 2017;547:E1-E3.
29. Yu M, Bardia A, Wittner BS, et al. Circulating breast tumor cells exhibit dynamic changes in epithelial and mesenchymal composition. Science 2013;339:580-4.

30. Chen X, Bode AM, Dong Z, et al. The epithelialmesenchymal transition (EMT) is regulated by oncoviruses in cancer. FASEB J 2016;30:3001.

31. Ellis H, Ma CX. PI3K Inhibitors in Breast Cancer Therapy. Curr Oncol Rep 2019;21:110.

32. Xia C, Liu Y, Chen Z, et al. Involvement of Interleukin 6 in Hepatitis B Viral Infection. Cell Physiol Biochem 2015;37:677-86.

33. Jung-Ta K, Lai HC, Shu-Mei T, et al. Rather than interleukin-27, interleukin-6 expresses positive correlation with liver severity in naïve hepatitis B infection patients. Liver Int 2012;32:928-36.

34. Argentou N, Germanidis G, Hytiroglou P, et al. TGF- $\beta$ signaling is activated in patients with chronic $\mathrm{HBV}$ infection and repressed by SMAD7 overexpression after successful antiviral treatment. Inflamm Res 2016;65:355-65.

35. Lamouille S, Xu J, Derynck R. Molecular mechanisms of epithelial-mesenchymal transition. Nat Rev Mol Cell Biol 2014;15:178-96.

36. Taniguchi K, Karin M. IL-6 and related cytokines as the critical lynchpins between inflammation and cancer. Semin Immunol 2014;26:54-74.

37. Feng X, Ke J, Li S, et al. FAF1 phosphorylation by AKT accumulates TGF- $\beta$ type II receptor and drives breast cancer metastasis. Nat Commun 2017;8:15021.

38. Tsai JH, Yang J. Epithelial-mesenchymal plasticity in carcinoma metastasis. Genes Dev 2013;27:2192-206.

39. Liu Y, Cheng LS, Wu SD, et al. IL-10-producing regulatory B-cells suppressed effector T-cells but enhanced regulatory T-cells in chronic HBV infection. Clin Sci 2016;130:907.

40. Trehanpati N, Vyas AK. Immune Regulation by T Regulatory Cells in Hepatitis B Virus-Related Inflammation and Cancer. Scand J Immunol 2017;85:175-81.

Cite this article as: Yu P, Liu P, Li N, Xie X, Tang H, Wu J, Kong Y, Xie X, Ye F. Hepatitis B virus infection specially increases risk of liver metastasis in breast cancer patients: a propensity-matched analysis. Transl Cancer Res 2020;9(3):1506-1517. doi: 10.21037/tcr.2020.01.63 